Cad.Est.Ling., Campinas, 48(1):125-134, 2006

\title{
ORGANIZAÇÃO TÓPICA DO DISCURSO DE SEQÜÊNCIAS DE TIRAS DIÁRIAS DE QUADRINHOS
}

\author{
MARIA DA PENHA PEREIRA LINS
}

(UFES)

\begin{abstract}
This study focuses on the management of the discursive topic in sequences of comic strips and it is inscribed within the research area dedicated to the continuum oral/written. Taking a functionalist perspective, in special that of Textual Linguistics, the study considers the topic not a simple, discrete function, but a complex functional domain, a scaling notion that characterizes itself by the properties of central concern and relevance. Supported by research models of oral texts, mainly Koch et al. (1992), one sequence of comic strips produced by a Brazilian author is analyzed in a research type both qualitative and interpretative. The textual organization is detected in observing both linear and hierarchical levels, identifying topic introduction, maintenance and change strategies. The study shows that thematic continuity is guaranteed by the combination of linguistic and visual elements and is made by similar strategies used in both oral and written texts, in addition to those specific of comic sequences.
\end{abstract}

\section{INTRODUÇÃO}

A linguagem dos textos de quadrinhos caracteriza-se pelo seu caráter de complementaridade entre componentes verbais e visuais. Os diálogos parecem estar no entremeio do oral com o escrito, isto é, constituem um texto que é planejado para parecer não-planejado, mostram uma preocupação em se construir uma espontaneidade verbal, mas que, sabe-se, foi minuciosamente planejada anteriormente. Desse modo, esse gênero textual inclui-se dentro da questão do continuum fala-escrita.

Esse caráter de informalidade e sua elaboração fragmentada, principalmente no que se refere às tiras diárias, faz a aproximação deste texto com o texto falado, uma vez que a tira é constituída de quadros e os tópicos são desenvolvidos dia-a-dia, de tira para tira, numa sequiência em que inserções e mudanças de assuntos promovem continuidades e descontinuidades em sua organização global.

Constata-se que, apesar da descontinuidade temporal no que diz respeito à publicação das tiras de quadrinhos, há, no entanto, uma continuidade tópica, que apresenta semelhanças com a forma de organização tópica de textos falados, principalmente no que tange às estratégias relativas ao componente lingüístico.

Neste estudo, a definição de tópico, por seu nível de abrangência, inscreve-se numa abordagem semântico-discursiva, em que tópico é tratado como uma categoria discursiva, que se organiza em dois planos, e a análise da seqüência desenvolve-se a partir de uma perspectiva funcionalista do discurso, em que o desenvolvimento de tópicos é estudado tendo em vista o princípio da centração, que significa "falar-se de alguma coisa"; e a definição do limite de tópicos, a partir de uma distribuição em segmentos sucessivos. 
Partindo dessa definição de tópico, passa-se, então, à verificação de como essa categoria ${ }^{1}$ se comporta e se organiza dentro do discurso específico das tiras diárias de quadrinhos. Para isso, tomou-se como base o modelo de Koch et al. (1992), formulado para a descrição de um diálogo do Projeto NURC, e que se esquematiza assim: 1) identificar e delimitar unidades tópicas; 2) caracterizar as relações de interdependência hierárquica e seqüencial; 3) detectar traços reveladores da estrutura interna das unidades tópicas.

Assim, faz-se necessário observar as marcas que definem início, manutenção e fim de tópico. Entretanto, como essas marcas são facultativas, multifuncionais e co-ocorrentes, não devem constituir critério absoluto para a delimitação de tópicos (Fávero, 1999: 49). Em vista disso, torna-se necessário lançar mão da teoria sobre frame, proposta pela sócio-etnometodologia (Hymes, 1974; Goffman, 1986; Tannen, 1989; Tannen e Wallat, 1986), com o objetivo de ampliar a definição de tópicos dentro do fluxo da progressão temática.

$\mathrm{Na}$ análise da progressão temática são observados os fenômenos da continuidade/ descontinuidade, com base nas hipóteses a respeito da organização do texto falado, estabelecidas por Koch et al. (1991: 151), no que se refere à modalidade oral do uso da língua e do ponto de vista postulado para análise, que atestam o "teor de produção pouco planejável de antemão" e "aparente desestruturação do discurso oral", o que caracteriza, de acordo com a situação, a prevalência de modo pragmático em sua organização.

Assim, à semelhança metodológica do tratamento de dados de textos orais, nesta análise descreve-se como se configura o gerenciamento do tópico nas tiras seqüenciais de quadrinhos.

\section{A NOÇÃO DE TÓPICO DISCURSIVO}

Há um consenso entre estudiosos do discurso de que se cada enunciado, numa sequiência conversacional, é tópica, semântica ou pragmaticamente relevante para o enunciado diretamente seguinte ou precedente, a conversa como um todo se apresenta como coerente. Isso não significa que a ausência dessa relação acarrete incoerência. As rupturas, entre elas a digressão, que poderiam ser vistas como rupturas na conversação, são tratadas como a substituição de um conjunto de relevâncias tópicas corrente por outro, o que não implicaria necessariamente uma descontinuidade textual, já que o foco inicial pode voltar à tona (Dascal e Katriel, 1979).

A depreensão de tópicos em textos implica a necessidade de estabelecer o uso dos termos "assunto" e "tema". Goutsos (1996) afirma que o tópico representa um "fio unificado" que transpassa o texto como um todo e, assim, é expandido, ou seja, o tópico é visto como uma estrutura ou como um frame. Nesse caso, a análise centra-se menos em sobre "o que" e mais sobre "o como" se fala de determinado tema. Desse modo, aquilo de que se fala provém necessariamente do modo como se fala e tópico pode ser representado como uma estrutura organizada que opera tanto no interior quanto fora das fronteiras das sentenças. É o resultado de marcação de fronteiras.

Ao definirem "unidade discursiva" Koch et al. (1992: 361) concluíram que a dificuldade em operar com esse conceito deveu-se ao caráter vago e amplo do significado de "assunto",

${ }^{1} \mathrm{O}$ termo categoria foi usado para designar o tópico discursivo como unidade de análise, em analogia a outros campos da lingüística, como a noção de categorias funcionais (Borba, 1976). Nos estudos de Análise da Conversação, o tópico discursivo é visto como uma categoria abstrata, primitiva, relacional, cujos traços definidores são a centração e a organicidade. Representa uma base para a descrição da estrutura da organização tópica de textos (Koch et al., 1992). 
Cadernos de Estudos Lingüísticos 48(1) - Jan./Jun. 2006

além do conseqüente grau de subjetividade que preside a compreensão dessa noção, além de "assunto" estar sempre associado a "tema", o que pode tornar a explicação circular. Os autores explicam que são duas as propriedades definidoras de tópico: a de centração e a de organicidade. A primeira abrange os traços concernência, relevância e pontualização; a segunda compreende as relações de interdependência de superordenação e sub-ordenação nos planos hierárquico e seqüencial, em que os níveis de hierarquização são caracterizados a partir de denominações tais quais segmento tópico, subtópico, quadro tópico e supertópico.

É possível detectar as mudanças tópicas a partir de nova centração, que, muitas vezes é percebida por uma substituição do conjunto de referentes. Para Brown e Yule (1983), a extensão de um tópico está relacionada à manutenção do tema e da relevância. Assim, se a relação semântica entre enunciados fica evidenciada, detecta-se no texto continuidade tópica. Possíveis rupturas não trazem necessariamente incoerência, uma vez que, numa visão global, essas rupturas podem ser vistas como descontinuidades. Para Koch (1992), as descontinuidades no sequienciamento tópico acontecem por processos de inserção e por processos de reconstrução.

\section{PROGRESSÃO TÓPICA EM SEQÜÊNCIA DE TIRAS DE QUADRINHOS}

Os textos de quadrinhos são classificados como criações episódicas por Quella-Guyot (1990), na medida em que mostra a cena e faz as personagens falarem. Além disso, apresentam um caráter de informalidade, o que propicia uma análise da organização tópica desse gênero textual, tendo como ponto de partida modelo utilizado para estudar textos falados. É com essa perspectiva que é apresentada a análise de uma seqüência de tiras de quadrinhos, de autoria de Miguel Paiva, com interações criadas em torno do personagem Gatão de Meia Idade. A sequiência de 63 tiras, foi selecionada de publicações do jornal O Globo, do Rio de Janeiro, no período compreendido entre 20 de agosto a 21 de outubro de 2001.Paiva identifica o personagem como "o retrato preciso das contradições do nosso tempo", "com seu rabo de cavalo e uma discreta angústia por chegar aos quarenta anos, o Gatão expõe sua malícia para sobreviver no mundo dos descasados, com descontração, irreverência e muito charme".

Esta série de segmentos tópicos ${ }^{2}$ mostra um homem maduro (Gatão) diante do mundo em transformação, refletindo sobre dúvidas e problemas relacionados ao comportamento da mulher e às premissas que tem sobre o que as mulheres pensam dos homens. Especialmente no tocante aos assuntos referentes à relação homem/mulher, o autor organiza os segmentos tópicos, utilizando-se do recurso retórico de fazer perguntas e respostas combinadas com o elemento visual. Trata da eterna discordância que existe entre os sexos masculino e feminino de modo metafórico, fazendo analogia com guerra e traz à tona assuntos como violência, novidades tecnológicas, terrorismo, conflitos, depressão, tão discutidos atualmente, aproveitando para fazer ancoragem pragmática com os acontecimentos contemporâneos.

A esquematização do nível hierárquico da sequiência de tiras pode ser elaborada como a seguir:

${ }^{2}$ Partindo da definição de Koch et al. (1992) de que unidade tópica é um fragmento recoberto por um mesmo tópico, foi feita a equivalência de uma tira com um segmento tópico, considerando que essa unidade atende, também, às características de parágrafo ou episódio de van Dijk (1992), de episódio conversacional de Crow (1983) e segmento tópico de Fávero (1999). 
LINS - Organização tópica do discurso...

1.Quadro tópico: Masculino vs Feminino

1.1. Subtópico nível 1 - Questionamento sobre a mulher

Segmentos tópicos:

Transar todo dia [tira 1] - não gostam

Futebol na TV [tira 2] - não prestam atenção

Toalete [tira 3\} vão com amigas

Fingimento [tira 4] - fingem orgasmo

Opinião [tira 5] - não gostam de opinião sincera

Elogio [tira 6] - parecem não ser francas

Separação [tira 7] - vão realmente embora

1.2 .Subtópico nível 1 - Questionamentos sobre o homem

Choro [tira 8] - choram

Idade [tira 9] - os de 40 são revoltados

Força [tira 10] - têm mais força física

Espera [tira 11] - não gostam de esperar mulheres

Flerte [tira 12] - olham para as mulheres

Juventude [tira 13] - gostam de parecer jovens

Entendimento [tira 14] - não entendem as mulheres

1.3.Subtópico nível 1 - Homens vs Cultura Responsabilidade [tira 15] - homens levam o mundo nas costas

Fragilidade [tira 16] -Gravidez fragiliza mulheres

Conquista [tira 17] - Homens são conquistadores

Educação [tira 18] - Homens têm maus hábitos

Casamento [tira 19] - Homens querem mulher, mãe, amiga

Culpa [tira 20] - Homens são sempre culpados

Estado [tira 21] - Homens perdidos na selva 1.4.Subtópico nível 1: Guerra dos Sexos Guerra cirúrgica [tira 43] - Mulheres fazem cirurgia plástica

Ataque aéreo [tira 44] - Mulheres atiram objetos
Ataque aéreo [tira 45] - Homens atiram objetos

Guerra psicológica [tira 46] - Homens e mulheres vão ao analista

Guerra bacteriológica [tira 47] - Mulheres chamam homens de verme

A mãe das guerras [tira 48] - Sogra é a mãe das guerras

Retirada estratégica [tira 49] - Casais separam-se

2. Quadro tópico: Novos tempos

2.1. Subtópico nível 1 - Violência

2.1.1. Subtópico nível 2 - Terrorismo Aviões [tira 27] - Ataques terroristas Pesadelo [tira 28] - Terroristas criam pesadelo

Alvo [tira 29] - O alvo do terror é o povo

A esmo [tira 30] - Terrorismo em qualquer lugar

Mundo [tira 31] - Terrorismo em todo o mundo

Brasil [tira 32/33] - Problemas do Brasil

Capitalismo [tira 34] - Ritual antropológico

Filhos [tira 35] - Preocupação com segurança

2.1.2. Subtópico nível 2 - Guerra

Guerra na TV [tira 57] - Na Tv parece game

Guerra no Brasil [tira 58] - Medo de guerra Guerra e aulas [tira 59] - Com guerra não há aulas

Recursos eletrônicos [tira 60] - Imagem parece chuvisco

Poderosos [tira 61] - Bush, Blair, Bin Laden

Turismo [tira 62] - Guerra perjudica

Pacifista [tira 63] - Não se alistar

2.2. Subtópico nível 1 - Inovações

2.2.1. Subtópico nível 2 - Novos Tempos

Consciência [tira 50] - Usar camisinha

Yuppies [tira 51] - Novos hippies são profissionais

Sexo virtual [tira 52] - Novos hippies fazem sexo virtual 
Cadernos de Estudos Lingüísticos 48(1) - Jan./Jun. 2006

Profetas [tira 53] - Novos hippies fazem Realização [tira 25] - Dinheiro ou amor protestos

Droga [tira 54] - Cigarro, uísque, TV

Dinheiro [tira 26] - Capital ou espírito

Nudismo [tira 55] - Colônias de nudismo

Paz e amor [tira 56] - Power Ranger

2.3. Subtópico nível 1 - Consequiências

2.3.1. Subtópico nível 2 - Conflitos

2.3.2. Subtópico nível 2 - Depressão

Estresse [tira 36] - Ficar estressado

Estresse [tira 37] - Ficar muito estressado

Insônia [tira 38] - Ter insônia

Carência [tira 39] - Ficar carente

Tratamento [tira 22] - Ser carinhoso ou duro

Homem [tira 23] - Gandaia ou paz espiritual

Relações [tira 24] - Pensar em si ou nos

Porre [tira 40] - Tomar um porre

Isolamento [tira 41] - Sentir-se num buraco

Paz [tira 42] - Voltar à paz outros

O esquema acima mostra uma forma de organização que pode ser definida como prototipicamente linear. Cada subtópico reúne segmentos tópicos contíguos, só passando a outro subtópico depois do esgotamento do anterior. Diferentemente do verificado em outras sequiências de quadrinhos (O amigo da onça, $\mathrm{O}$ menino maluquinho, Marly $)^{3}$, em que os segmentos tópicos aparecem de maneira desordenada, esta sequiência apresenta uma organização bem elaborada. Há ruptura da linearidade apenas quando o autor aborda acontecimento histórico, aproveitando para fazer uma ancoragem pragmática. Observa-se que a temática enfocada nos segmentos 22 a 26 é o conflito do homem moderno entre escolher aproveitar a vida ou preocuparse com o espírito. No segmento 27, publicado no dia 14 de setembro de 2001, três dias depois do atentado às torres gêmeas nos Estados Unidos, é mostrado o personagem-título olhando para o céu e afirmando que "há realmente algo entre o céu e a terra, além dos aviões de carreira". O texto de cabeça-de-tira, que indica início de novo subtópico, informa: "Este mundo está um terror", conforme se pode observar nas tiras mostradas a seguir.

Tira 22

\section{GATÃO DE MEIA-IDADE}
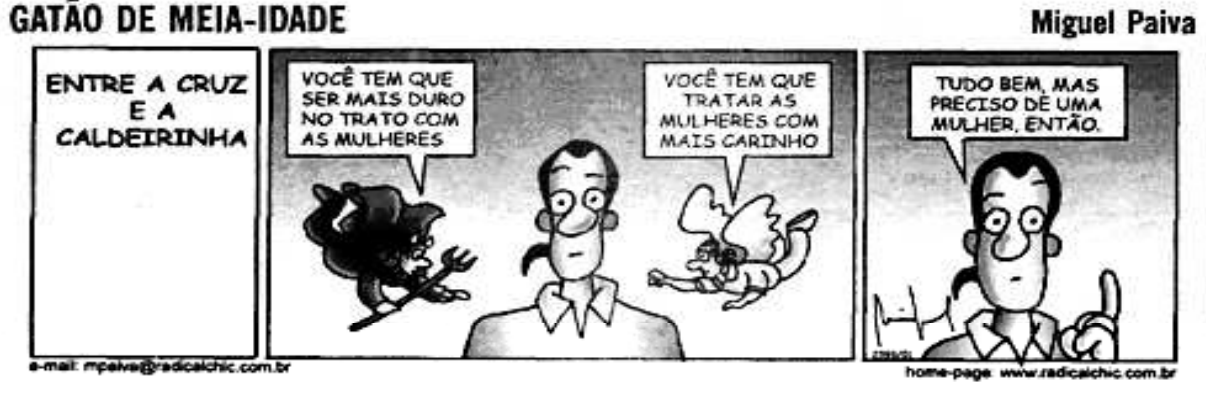

$10 / 09 / 2001$

\footnotetext{
${ }^{3}$ Estudos apresentados em: LINS, Maria da Penha Pereira (2004).
} 
GATÃO DE MEIA-IDADE

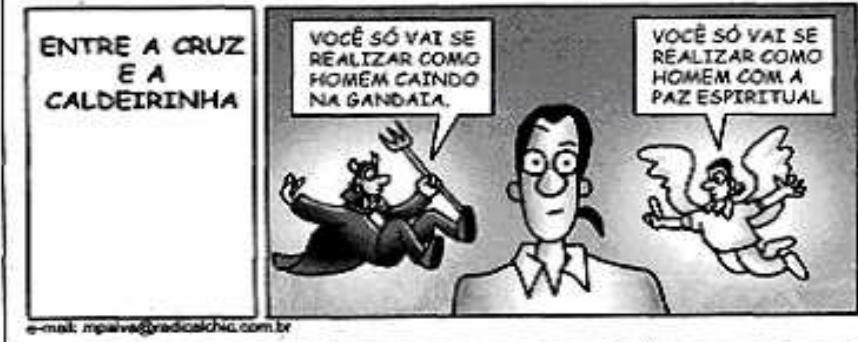

Miguel Paiva

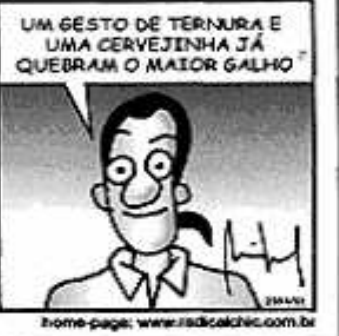

$11 / 09 / 2001$

Tira 24

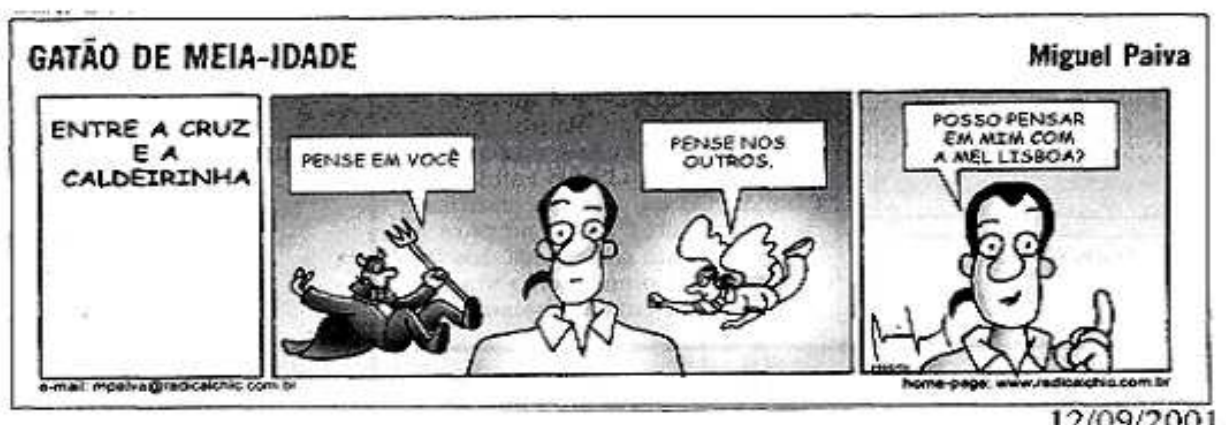

Tira 25

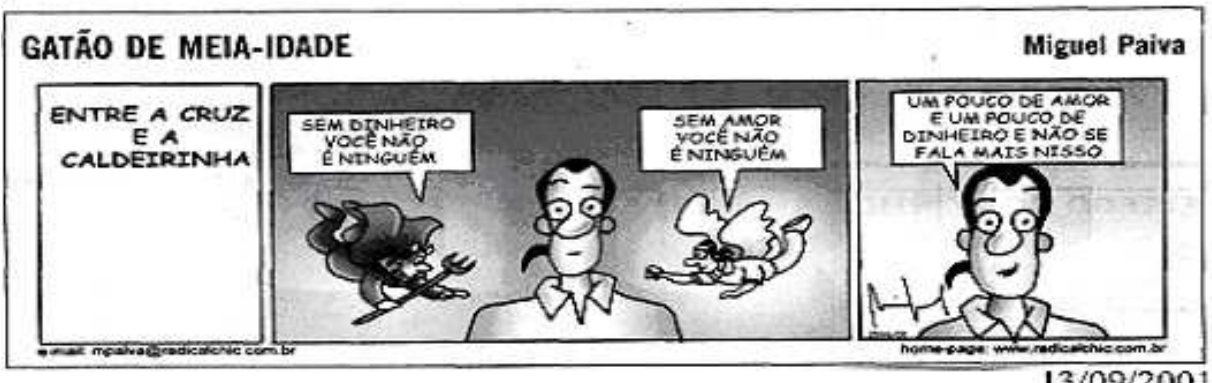

$13 / 09 / 2001$ 


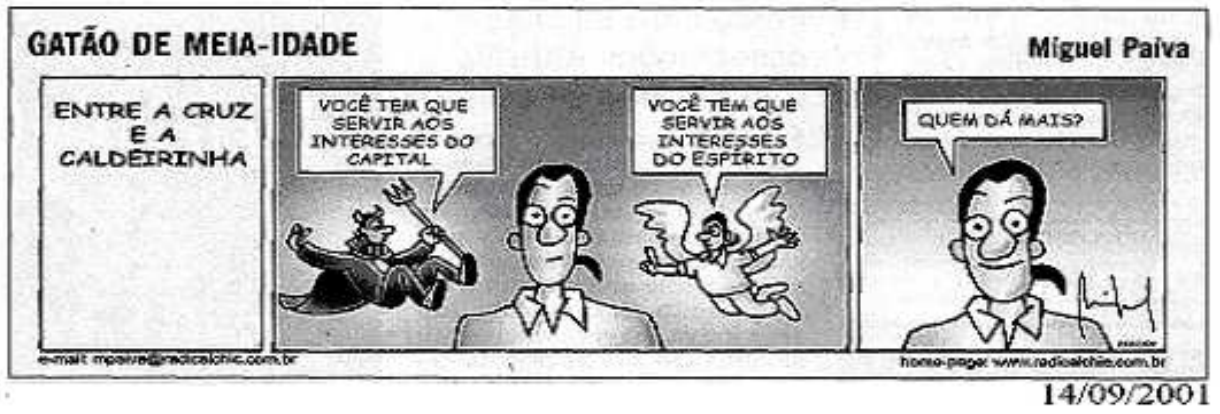

Tira 27

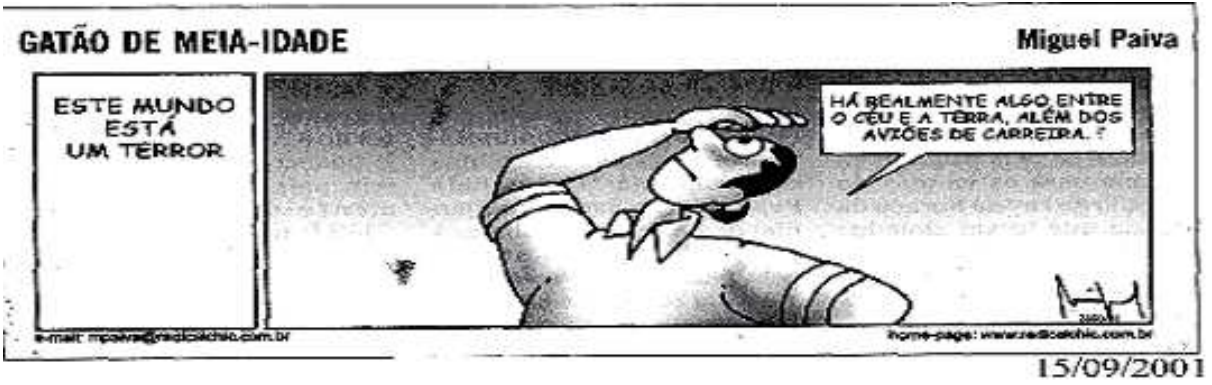

Em sequiência, até a tira 35, os assuntos abordados nos segmentos são relativos ao ato terrorista. A tira seguinte, 36, começa a tratar do tema "depressão", que é expandido até 42. Ambos os subtópicos, Terrorismo e Depressão, pertencem ao mesmo quadro tópico, Novos Tempos.

Se levarmos em conta que a impressão primeira que se tem de tiras de quadrinhos é a de que a cada dia um tópico diferente é enfocado e exaurido e que não há nenhuma ligação de umas com outras tiras, pode-se afirmar, a partir da observação do esquema acima, que na sequiência analisada, assim como em conversações espontâneas, tópicos são desenvolvidos, continua e descontinuamente, de forma coerente e em camadas, na direção de um tema mais amplo, abordando, em seus segmentos, assuntos relacionados a um mesmo frame, o que é marcado lingüística e visualmente.

Isto significa uma ampliação razoável de um tópico, que se expande em termos de temática, abrangendo, no que diz respeito à escala hierárquica, subtópicos e quadro tópicos. No que se refere a quadrinhos, considerando-se que a cada dia somente uma tira é publicada, observa-se que muitos quadros tópicos estendem-se por até um mês de publicação. Como acontece com uma conversa informal, verifica-se que uma abordagem tópica, às vezes, é mais desenvolvida, expandindo-se por um longo conjunto de segmentos contíguos ou não, e que outras não vão muito adiante, abrangendo poucos segmentos. Isso revela que um tópico esteve em proeminência por grande extensão, chegando a compor um quadro tópico, consideradas aí as descontinuidades. 
O desenvolvimento de cada um dos subtópicos parece corroborar, nas sequiências de tiras de quadrinhos, a constatação de pesquisadores que analisam textos falados. Assim como nestes, naquelas parece haver um movimento temático progressivo, do tipo "uma coisa puxa outra", que, dentro de uma visão global, parece fornecer continuidade ao texto.

Diferentemente da conversa espontânea, em que a negociação dos tópicos é feita colaborativamente entre os interlocutores, e semelhantemente à carta pessoal, em que os temas são propostos pelo emissor (Paredes Silva, 1995: 235)4, nas seqüências de quadrinhos o autor propõe os temas, escolhe como e quando introduzi-los e o momento apropriado para encerrálos, sem envolver a disputa de tomada de turnos; apresenta-se como um diálogo assimétrico. Ao leitor cabe a aceitação tácita, uma vez que esse gênero tem um público específico que, de certa maneira, possui esquemas prévios quanto à temática que o segmento diário vai abordar, já que é conhecedor dos aspectos que dizem respeito à composição do texto, como mundo de referência, cenário, personagens e possíveis assuntos a serem abordados.

A análise da seqüência de tiras, assim como a análise de cartas pessoais, conforme demonstrou Paredes Silva, remetem à noção de Tannen (1985) de que há um continuum nas relações fala/escrita, uma vez que ambos, embora representem textos escritos caracterizados, por isso, por um certo grau de planejamento prévio, apresentam características de texto falado e utilizam em suas construções estratégias de gerenciamento do tópico próprias da conversação.

Tanto é, que a sequiência "Ser gatão de meia idade é...", apesar das suas salientes características de texto falado, em termos de continuum, aproxima-se do texto escrito, na medida em que introduz um subtópico, desenvolve e termina; só, então, inicia outro.

Além disso, no que se refere às condições de produção, o texto composto por uma sequiência de tiras de quadrinhos alinha-se a outros gêneros escritos. Ele apresenta diversas das características distintivas da escrita apontadas por Fávero et al. (2002: 74): 1) interação à distância (espaço-temporal); 2) planejamento anterior à produção; 3) criação individual; 4) possibilidade de revisão; 5) livre consulta; 6) reformulação; 7) impossibilidade de acesso imediato; 8) impossibilidade de processamento do texto a partir de reações do leitor; 9) tendência a esconder o processo de criação, mostrando apenas o resultado.

Essa dubiedade do texto de quadrinhos decorre do fato de que ele é, por natureza de produção, um texto escrito; mas, por natureza de recepção, oral. Esse objetivo de mostrar-se um texto falado verifica-se pela organização de tópicos discursivos e, também, pela característica de ser dialogado e construído em linguagem informal.

Ao tratar de processos de retextualização, Marcuschi (2001: 32) ensina que o texto falado em hipótese alguma representa um texto "descontrolado e caótico" e que o texto escrito representa um texto "controlado e bem formado". O que ocorre no processo de retextualização não é a passagem do caos para a ordem, mas a passagem de uma ordem para outra ordem. Esse raciocínio de Marcuschi pode ser aplicado às sequiências de tiras diárias de quadrinhos. Nelas tópicos variados se interligam e o leitor de tiras sabe como encadeá-las e como entender as produções lingüísticas e visuais a elas inerentes, porque domina o enquadre referente ao gênero quadrinhos. Por comparação, então, o texto de quadrinhos representaria a combinação dessas duas ordens, imbricadas numa só. Nessa linha de raciocínio, pode-se afirmar que o texto de quadrinhos é escrito para parecer falado, e, por conseguinte, um texto construído em discurso elaborado para parecer um discurso corrente.

\footnotetext{
${ }^{4}$ Paredes Silva afirma que a carta pessoal se aproxima da conversa espontânea, uma vez que diferentes tópicos se sucedem com relativa "à vontade" numa mesma carta e cita Kayser (1967), que compara a carta a uma "conversa solta".
} 
Cadernos de Estudos Lingüísticos 48(1) - Jan./Jun. 2006

Fazendo considerações sobre a configuração do hipertexto eletrônico, Koch (2000) salienta que, do ponto de vista da produção, os links com função dêitica monitoram o leitor no sentido da seleção de focos de conteúdo e que representam operadores de coesão, à disposição dos leitores para fazê-los funcionar como orientadores da hiperleitura na direção de sentidos coerentes e compatíveis com a perspectiva postulada no todo do hipertexto que a hospeda, evitando que seja desviada para a incongruência e sustentabilidade dos posicionamentos assumidos naquele texto eletrônico. Para a autora, também no hipertexto, os princípios da topicidade e da relevância têm sua validade.

Sob certos aspectos, pode-se considerar uma seqüência de tiras de quadrinhos como um hipertexto. O leitor busca pistas nos componentes visuais e lingüísticos, relaciona-as aos esquemas de conhecimento prévios sobre tiras de quadrinhos que já tem internalizados e busca a coerência, relacionando tópicos e caminhando na direção de uma temática mais ampla.

Ao tratar de tópicos que se desenvolvem progressivamente e de tópicos com fronteiras, Mondada (2001) constata que os tópicos que se desenvolvem progressivamente são próprios de uma boa conversação, em que nem bem se acaba de falar de um tópico já se começa outro, ou seja, há uma certa fluidez. Em oposição, os tópicos com fronteiras claramente delimitadas são característicos de interações formais, em que os locutores consideram importante tratar exclusivamente de um tópico. Nas transições progressivas, a preferência é por temáticas abertas. A autora cita Sacks (1992), para afirmar que essa diferença se traduz em duas maneiras diferentes de falar: 1) falar sobre um tópico e 2) falar topicalmente. No interior de uma perspectiva que reconhece um continuum entre fala e escrita, pode-se considerar que "falar sobre um tópico" se aproximaria da escrita, por sua organização, e que "falar topicalmente" se aproximaria da fala, por seu afrouxamento na gestão do tópico.

Esses dois processos podem ser depreendidos na organização das tiras de quadrinhos em geral. Ora os autores falam sobre um tópico, ora falam topicalmente. Miguel Paiva (Gatão de meia idade), por exemplo, só se permite falar de outro tópico quando esgota o anterior. Já outros como Ziraldo (O menino maluquinho), Péricles ( $\mathrm{O}$ amigo da onça), Milson Henriques (Marly) preferem "falar topicalmente", isto é, de maneira mais solta, indo e voltando no desenvolvimento do tópico.

Também, pode-se aplicar às seqüências de tiras de quadrinhos a parceria entre interlocutores salientada por Koch (1999), na produção de sentido. A coerência não está apenas no texto, mas resulta de uma construção dos parceiros na situação interativa. É de interesse dos parceiros que a conversação flua. Desse modo, a descontinuidade na apresentação de uma tira a cada dia e a aparente descontinuidade na apresentação de diferentes tópicos a cada dia não se consubstanciam, na media em que, vale a pena insistir, o leitor de quadrinhos conhece as pistas que a linguagem própria do gênero concede, e atua, durante sua interpretação, dentro de um frame, corporificado por um personagem-título, num caminho referente à temática e ao mundo de referência de cada um dos diferentes autores.

\section{$\overline{\text { REFERÊNCIAS BIBLIOGRÁFICAS }}$}

BROWN, G. e YULE, G. (1983). Discourse analysis. Cambridge: University Press.

CROW, B. K. (1983). Topic shifts in couples conversations. In: CRAIG, R. T. e TRACY, K. Conversational coherence. California: Sage Publications. 
DASCAL, M. e KATRIEL, T. (1979). Digressions: a study in conversational coherence. In: PETÖFI, J. S. (org.). Text vs sentence. Hamburgo: Buske. pp,76-95.

DIJK, T. van. (1996). Cognição, discurso e interação. (org. Ingedore Koch). São Paulo, Contexto.

FÁVERO, L. L. (1999). O tópico discursivo. In: PRETI, D. (org.) Análise de textos orais. 4ed. São Paulo: Humanitas.

FÁVERO, L. L. et al. (2002). Oralidade e escrita: perspectivas para o ensino de língua materna. 3ed. São Paulo: Cortez.

GOFFMAN,E. (1986). Frame analysis. Boston: Northeastern Univ. Press.

GOUTSOS, D. (1996). Modelling discourse topic: sequential relations and strategies in expository text. Norwood, New Jersey: Ablex Publishing Corporation.

KOCH, I. V. (1992). Organização tópica da conversação. In: Contexto. pp. 71-115.

KOCH, I. V. et al. (1992). Organização tópica da conversação. In: ILARI, R. (org.) Gramática do Português falado. Campinas: UNICAMP. v.2. pp. 359-447.

KOCH, I. V. et al. (1991). Aspectos do fluxo de informação no discurso oral dialogado. In: CASTILHO, Ataliba T. (org.) Gramática do português falado. 2ed. Campinas: UNICAMP/FAPESP.

KOCH, I. V. (2000). Coerência e manutenção temática no hipertexto. ABRALIN.

LINS, M. da P. P. (2004). Organização tópica do discurso de tiras de quadrinhos. Tese de Doutorado. Rio de Janeiro: UFRJ.

MARCUSCHI, L. A. (2001). Letramento e oralidade no contexto das práticas sociais e eventos comunicativos. In; SIGNORINI, Inês. (org.) Investigando a relação oral/escrito. Campinas: Mercado de Letras.

MONDADA, L. (2001). Gestion du topic et organization de la conversation. Cadernos de estudos lingüísticos. Campinas. nº 41. Jul/Dez. pp. 7-36.

PAREDES SILVA, V. L. (1995). Ao correr da pena. In: HEYE, J. (org.) Flores verbais. Rio de Janeiro: Ed 34.

QUELLA-GUYOT, D. (1990). A história em quadrinhos. (trad. Maria Stela Gonçalves e Adail Ubirajara Sobra). São Paulo: Unimarco/ Loyola.

TANNEN, D. (1985). Relative focus on involvement in oral and written discourse. In: OLSON, D; TORRANCE, N. e HUDYARD, A. (eds) Literacy, language and learning. Cambridge: Univ. Press.

TANNEN, D. \& WALLAT, C. (1986). Interactive frames and knowledge schemas in interaction. In: TANNEN, D. (ed). Framing discourse. New York: Oxford Univ. Press. 